\title{
Laboratory-based surveillance for Cryptosporidium in France, 2006-2009
}

The ANOFEL Cryptosporidium National Network ${ }^{1}$

1. Details of the corresponding author and the list of members of the network are included at the end of the article

Citation style for this article:

The ANOFEL Cryptosporidium National Network. Laboratory-based surveillance for Cryptosporidium in France, 2006-2009. Euro Surveill. 2010;15(33):pii=19642.

Available online: http://www.eurosurveillance.org/ViewArticle.aspx?Articleld=19642

In 2002, the French Food Safety Agency drew attention to the lack of information on the prevalence of human cryptosporidiosis in the country. Two years later, the ANOFEL Cryptosporidium National Network (ACNN) was set up to provide public health authorities with data on the incidence and epidemiology of human cryptosporidiosis in France. Constituted on a voluntary basis, ACNN includes 38 hospital parasitology laboratories (mainly in university hospitals). Each laboratory is engaged to notify new cases of confirmed human cryptosporidiosis, store specimens (e.g. stools, duodenal aspirates or biopsies) and related clinical and epidemiological data, using datasheet forms. From January 2006 to December 2009, 407 cryptosporidiosis cases were notified in France and 364 specimens were collected. Of the notified cases, 74 were children under four years of age, accounting for $18.2 \%$. HIVinfected and immunocompetent patients represented $38.6 \%(n=157)$ and $28 \%(n=114)$ of cases, respectively. A marked seasonal pattern was observed each year, with increased number of cases in mid to late summer and the beginning of autumn. Genotyping of 345 isolates from 310 patients identified C. parvum in 168 (54.2\%) cases, C. hominis in 113 (36.4\%) and other species in 29 (9.4\%), including C. felis $(n=15)$, C. meleagridis $(n=4), C$. canis $(n=4)$, Cryptosporidium chipmunk genotype $(n=1)$, Cryptosporidium rabbit genotype $(n=1)$ and new Cryptosporidium genotypes $(n=4)$. These data represent the first multisite report of laboratory-confirmed cases of cryptosporidiosis in France.

\section{Introduction}

Cryptosporidium infection is increasingly recognised as a major cause of diarrhoeal disease worldwide, in all age groups [1]. The range of people affected is broad including immunosuppressed people and children, especially in developing countries. Sporadic or outbreak cases are also seen among immunocompetent individuals. Symptoms of the disease are diverse: $90 \%$ of patients have diarrhoea, which is often associated with other gastrointestinal symptoms such as vomiting, nausea or abdominal pain [1]. Asymptomatic infections are also reported. In immunocompromised individuals, such as people receiving immunosuppressive drugs and acquired immunodeficiency syndrome (AIDS) patients with low CD4 lymphocyte counts, cryptosporidiosis is often chronic, leading to important weight loss and cachexia. Currently, very few drugs are active against Cryptosporidium and none is curative: the only antiparasitic drug proven to be effective in immunocompetent adults and children is nitazoxanide, and none has proven effective in severely immunocompromised patients [2].

Over the past 20 years, Cryptosporidium has been responsible for numerous waterborne outbreaks of gastrointestinal disease, mainly in North America and the United Kingdom, but also throughout the world $[3,4]$. These outbreaks have been described in relation to drinking contaminated water or recreational use of contaminated water, consumption of contaminated food, person-to-person spread and animal-to-person contact [5]. Cryptosporidium species are of major concern for regulatory agencies, water industries and consumers [6], because they are widespread zoonotic pathogens and because oocysts (the transmissible form of the parasite) are resistant to chemical disinfectants used for treating drinking water.

Although the role of water and food in the epidemiology of cryptosporidiosis is now clearly recognised, the prevalence of Cryptosporidium spp. infection in humans is not well known. In several countries, notification of confirmed cases to public health agencies is an essential stage of national strategies to improve both prevention of Cryptosporidium infection and the understanding of cryptosporidiosis epidemiology [4,5,7-10]. In France, most laboratories do not test for Cryptosporidium in stool specimens submitted for routine parasitological examination and sporadic cases are not reported at regional or national level. For this reason, cryptosporidiosis remains underdiagnosed and underreported. Nevertheless, three cryptosporidiosis outbreaks have been documented in France. The first occurred in Sète (Hérault) in 1998, the second in Dracy-le-Fort (Saône et Loire) in 2001, and the last in Divonne-les-Bains (Ain) in 2003, involving 150, more than 480 and 727 estimated cases, respectively [11-13]. 
To deal with a recognised but poorly defined risk of cryptosporidiosis in immunocompetent and immunocompromised populations, the French Food Safety Agency (Agence française de sécurité sanitaire des aliments, Afssa) asked an expert group to assess the risk of food-borne and waterborne cryptosporidiosis in France. The group was set up in January 2001: on the basis of its final report in 2002, Afssa pointed out the lack of information on human cryptosporidiosis in France and strongly suggested improving surveillance by improving investigation means for Cryptosporidium in humans, animals and foods (including water resources) [14]. As a result of this report, a network of laboratories - the ANOFEL Cryptosporidium National Network (ACNN) - covering most of the French territory was established in October 2004 to provide public health authorities with information on the incidence and epidemiology of human cryptosporidiosis in France. It was set up on a voluntary basis by the French association of medical parasitologists (Association des enseignants et des praticiens hospitaliers titulaires de parasitologie et mycologie médicales, ANOFEL) with the support of Afssa and the national institute of disease surveillance (Institut de veille sanitaire, InVS). Established with 31 hospital parasitology laboratories (mainly university hospitals) distributed all over the national territory (metropolitan France and overseas departments of French Guiana, Guadeloupe and Martinique), the network initially focused on internal organisation and interlaboratory tests for microscopic diagnosis of cryptosporidiosis. Reporting of cryptosporidiosis cases and specimen collection started in January 2006.

\section{FIGURE 1}

Location of the 38 laboratories participating in the ANOFEL Cryptosporidium national network (ACNN), France, 31 December 2009

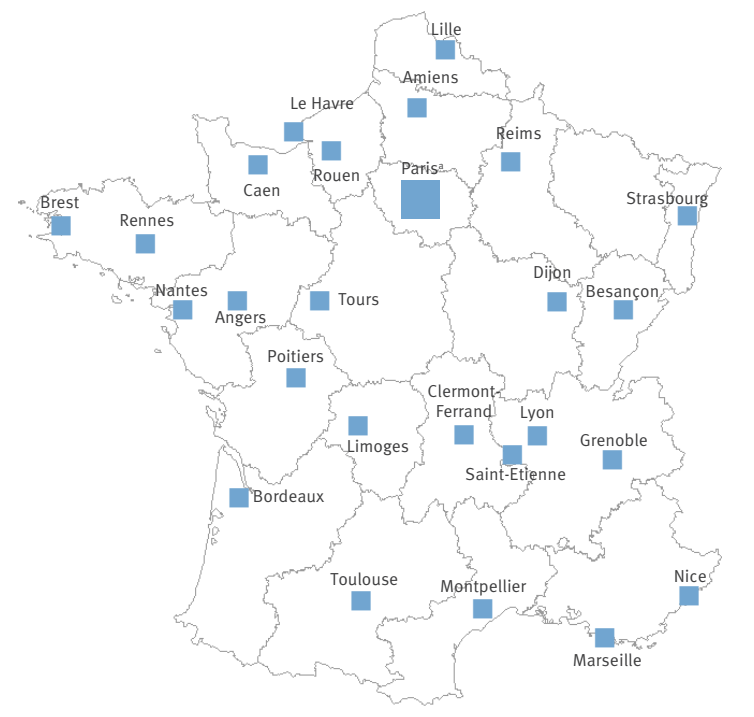

Also overseas departments:

Fort de France (Martinique)

- Pointe à Pitre (Guadeloupe)

- Cayenne (French Guiana)

ANOFEL: French association of medical parasitologists.

a There are 10 laboratories in the network in Paris.
By the end of the year, there were 36 participating laboratories; a further two joined in 2008 (Figure 1). This article summarises the Cryptosporidium-related data, including genotyping, collected from 2006 to 2009.

Since testing for Cryptosporidium is not included in routine parasitological stool tests in France, it is only performed at the physician's request or following the recommendation of the director of a laboratory, on the basis of available clinical or epidemiological patient data suggesting Cryptosporidium infection. An ACNN internal survey carried out in February 2010 revealed that routine testing for Cryptosporidium in stools of HIV-infected patients is performed by 27 participating laboratories (almost three quarters), by 50-60\% of laboratories in stool samples from patients with organ transplantation $(n=18)$, stem cell transplantation $(n=21)$ or lymphoproliferative disorder $(n=19)$ and by around $40 \%$ of laboratories in faecal samples from immunocompetent patients with diarrhoea $(n=15$ for samples from children; $n=13$ for samples from adults).

\section{Methods}

Data and specimen collection

Each laboratory in the ACNN was engaged to notify every new case of laboratory-confirmed human cryptosporidiosis. Diagnosis was based on the demonstration of Cryptosporidium spp. in stools, duodenal aspirates or intestinal biopsies (or in other sample in case of extraintestinal cryptosporidiosis) by microscopy, using modified Ziehl-Neelsen stain alone or in conjuction with polymerase chain reaction (PCR) (36 laboratories), Heine stain (one laboratory) and auramine stain (one laboratory) [15]. Diagnostic laboratory staff were asked to provide details (including age, sex and sample collection date) of cryptosporidiosis cases upon notification, using a standardised form. Related clinical and epidemiological data were also collected: patient's place of residence, history of recent foreign travel, animal and water exposure and whether the case was considered to be part of a family or household cluster or an outbreak. Faecal samples were collected, preserved in $\mathbf{2 . 5} \%$ (volume by volume) potassium dichromate solution and stored at $+4{ }^{\circ} \mathrm{C}$ until they were sent to the Lille or Lyon laboratories, which were in charge of Cryptosporidium spp. sample collection. More rarely, DNA extracts were sent to the collection and stored at $-20{ }^{\circ} \mathrm{C}$.

\section{Molecular characterisation of isolates}

Except for two laboratories that carried out genotyping by themselves (Dijon and Paris Pitié Salpétrière), molecular characterisation of isolates from other laboratories was performed in Lille. Genomic DNA was extracted from stool samples using the UltraClean Fecal DNA Kit (MoBio, Ozyme) according to the manufacturer's protocol. The species and genotype were determined using $18 \mathrm{~S}$ ribosomal DNA sequence analysis [16].

Data analysis

Case notifications were centralised in one laboratory (Lille). All collected information was entered into 
a Microsoft Excel database. Epidemiological analysis was published each year for members of the network. The comparative distribution of $C$. parvum and $C$. hominis cases in the dataset was analysed by Fisher's exact test.

\section{Results}

Details of laboratory-confirmed cryptosporidiosis cases

During the four-year study period, 42,004 stools samples from 24, 915 patients were tested for Cryptosporidium oocysts. A total of 407 laboratoryconfirmed cases of cryptosporidiosis were notified.

\section{FIGURE 2}

Reported cryptosporidiosis cases, ANOFEL Cryptosporidium national network (ACNN), France, 2006-2009 (n=407)

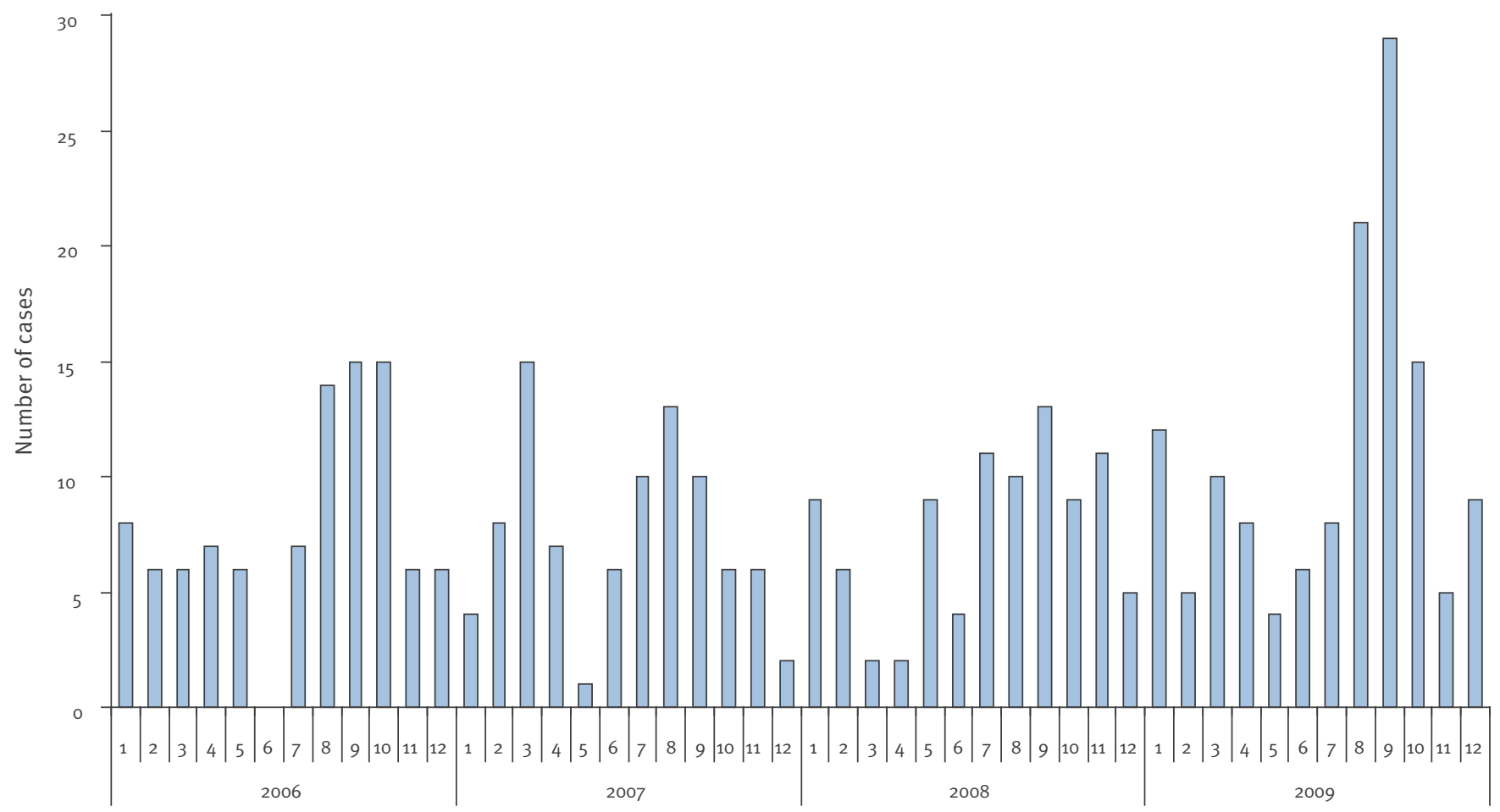

ANOFEL: French association of medical parasitologists.

\section{FIGURE 3}

Age distribution of cryptosporidiosis cases by immune status, ANOFEL Cryptosporidium national network (ACNN), France, 2006-2009 $(n=407)$

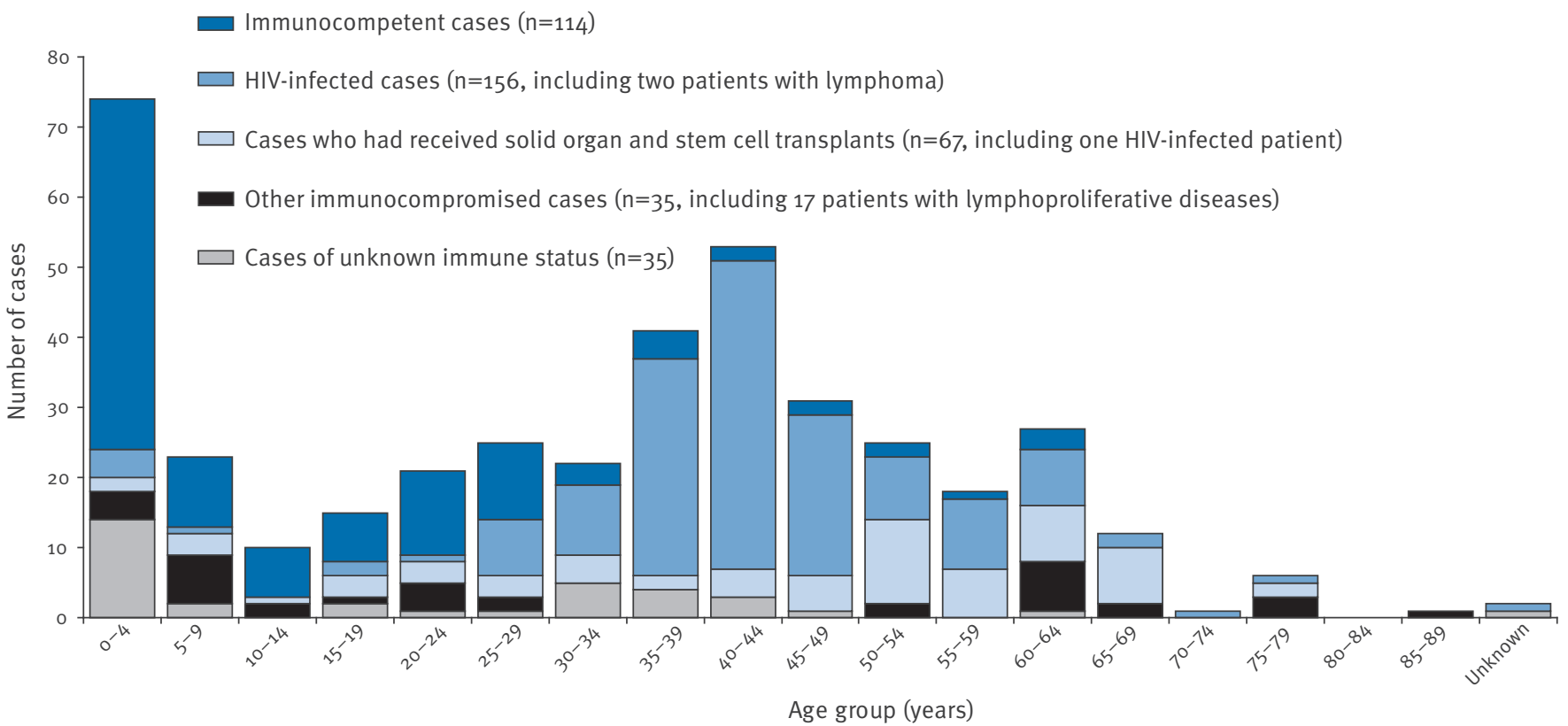

ANOFEL: French association of medical parasitologists; HIV: human immunodeficiency virus. 
The number of cases was fairly similar over the first three years: 96 in 2006, 89 in 2007 and 92 in 2008; in 2009, the number was higher, with 135 cases reported (five cases were reported twice, in two different years, and were therefore removed from the total). Cases were reported in almost all months of the study period, with peaks from mid/late summer to autumn each year (Figure 2). In 2007, the high number of notifications in March was related to a suspected outbreak in French Guiana.

Of the 407 cases, $253(62 \%)$ were male, 148 (36\%) were female (the sex of six patients was not documented). Overall, the male to female ratio was 1.7 (2.2 in 2006, 2.1 in 2007, 1.5 in 2008 and 1.4 in 2009). All age groups were represented (Figure 3). The age distribution was bimodal, with the greatest number of cases reported among children under the age of four years $(n=74$, $18.2 \%$ of cases), and among adults aged $35-49$ years $(n=125,30.7 \%$ of cases). In 2007, the cases in the age group 0-4 years included clustered cases $(n=9)$ of the suspected outbreak in Guiana (discussed below).

Information about immune status was available for 372 patients. Immunocompetent patients accounted for $28 \%(n=114)$, mainly children and young adults (under 24 years old) (Figure 3). A large proportion of the reported cases were HIV infected $(38.6 \%, n=157)$, accounting for $58.3 \%$ (56 of 96), 39.8\% (35 of 88), $34.1 \%$ (31 of 91) and $26.5 \%$ (35 of 132) of reported cases in 2006, 2007, 2008 and 2009, respectively. Most of the HIV-infected patients had CD4+ lymphocyte counts of less than 200 per $\mathrm{mm}^{3}$ (data not shown) and were in the age group 35-49 years (Figure 3). Other causes of immunosuppression accounted for $11.5 \%(n=11), 18.2 \%$ $(n=16), 27.5 \% \quad(n=25)$ and $39.4 \%(n=52)$ of cases in 2006, 2007, 2008 and 2009, respectively.

A total of 372 (91.4\%) cases had diarrhoea; 19 did not (unknown for 16 patients).

\section{TABLE 1}

Cryptosporidium species and genotypes detected by the ANOFEL Cryptosporidium National Network (ACNN), France, 2006-2009 $(\mathrm{n}=310)$

\begin{tabular}{|l|r|r|r|r|r|}
\hline \multirow{2}{*}{$\begin{array}{l}\text { Cryptosporidium } \\
\text { species or genotype }\end{array}$} & \multicolumn{6}{|c|}{ Number detected } \\
\cline { 2 - 6 } C. parvum & 2006 & 2007 & 2008 & 2009 & Total \\
\hline C. hominis & 32 & 33 & 51 & 52 & 168 \\
\hline C. felis & 30 & 22 & 14 & 47 & 113 \\
\hline C. meleagridis & 2 & 2 & 3 & 3 & 15 \\
\hline C. canis & 1 & 0 & 1 & 2 & 4 \\
\hline Chipmunk genotype & 0 & 0 & 1 & 0 & 1 \\
\hline Rabbit genotype & 0 & 0 & 0 & 1 & 1 \\
\hline Other genotypes & 1 & 0 & 2 & 1 & 4 \\
\hline Total & 73 & 57 & 73 & 107 & 310 \\
\hline
\end{tabular}

ANOFEL: French association of medical parasitologists.
Cryptosporidiosis clustered cases

During March and April 2007, 10 laboratory-confirmed cryptosporidiosis cases were passively reported in Cayenne, French Guiana. Nine were children under the age of two years and one adult. No epidemiological link between the cases was found (such as exposure to contaminated water or infected animals, or the location of the cases' homes) and the causative species of Cryptosporidium could not be identified (as samples were not sent for genotyping).

\section{Isolate collection and genotyping}

Over the study period, a total of 364 faecal specimens (or DNA extracts) from 328 patients were collected, corresponding to $80.6 \%$ of the notified cases. Of the 364 samples, 345 (94.8\%) were genotyped from DNA by PCR-sequencing of the $18 \mathrm{~S}$ rDNA locus. Among these, 35 specimens were received from 14 patients who were sampled at different dates during their cryptosporidiosis episode. In all these cases, the Cryptosporidium species identified in the sequential samples was indistinguishable from that of the initial specimen. Molecular characterisation of Cryptosporidium species in the 310 first specimens identified C. parvum in 168 (54.2\%) and C. hominis in 113 (36.5\%) (Table 1).

Other species or genotypes were identified in 29 patients $(9.4 \%)$. They were $C$. felis $(n=15), C$. meleagridis $(n=4), C$. canis $(n=4)$, Cryptosporidium chipmunk genotype $(\mathrm{n}=1)$, Cryptosporidium rabbit genotype $(n=1)$ and four different Cryptosporidium new genotypes (for each, $n=1$ ). 18S rDNA sequences of the four new genotypes presented $97 \%$ homology with both C. parvum and C. meleagridis, $99 \%$ with both C. hominis and Cryptosporidium rabbit genotype, $99 \%$ with Cryptosporidium cervine genotype and $96 \%$ with C. hominis. Species other than C. parvum and C. hominis were mostly found in patients with immune deficiencies (24 of 29); they were found in only five immunocompetent patients (Table 2).

The proportion of cases infected with C. parvum and C. hominis varied during this study. In 2006, each species was almost equally represented: 32 patients with C. parvum and 30 with C. hominis. In 2007, cases with C. parvum infection were present in a higher proportion (33 cases with C. parvum versus 22 with $C$. hominis) whereas cases with $C$. parvum were markedly overrepresented in 2008 ( 51 with C. parvum versus 14 with C. hominis) (Table 1). The 2008 distribution could not be related to an outbreak or another identified cause. In 2009 , the proportion of cases with C. parvum (48.6\%, $\mathrm{n}=52)$ and $C$. hominis $(43.9 \%, \mathrm{n}=47)$ was again similar. The monthly distributions of $C$. parvum and $C$. hominis cases did not reveal any specific seasonal pattern, but the case numbers per month were too small to determine seasonality (data not shown).

The comparative distribution of C. parvum and C. hominis cases was analysed, looking at the following parameters: age, sex, immune status, symptoms (diarrhoea, nausea, abdominal pain, fever and weight loss), 
location (rural or urban), whether the patient was part of a household cluster, and animal and water exposure (data not shown). C. parvum was more prevalent than C. hominis in patients above 60 years of age $(p=0.01)$ and weight loss was more frequently reported by patients infected with $C$. parvum than by those infected with $C$. hominis (p<0.03). No difference in the distribution of $C$. parvum and C. hominis was found between immunocompetent and immunocompromised patients. Within the group of immunocompromised patients, C. parvum was more prevalent than C. hominis in patients with haematological disorders (lymphoproliferative diseases and stem cell transplantations) ( $p<0.001$ ). C. hominis was more frequently associated than C. parvum with travel-related cryptosporidiosis ( $p<0.001)$, untreated drinking water ( $p<0.02)$ and the presence of diarrhoea in household contacts $(p=0.001)$.

\section{Discussion}

This article constitutes the first human cryptosporidiosis epidemiological report in France, based on a four-year national survey. Data analysis indicates that Cryptosporidium spp. are geographically widespread in France and can infect both sexes in all age groups. As already reported but not explained in other surveillance studies, males were more frequently infected than females. In our study, this could be related in part to the over-representation of HIV-infected patients, who were mainly male.

Cryptosporidiosis affected particularly children under four years of age. A high incidence of the disease in this age group has been reported in Canada [7], the United States [10], New Zealand [9] and Europe [4], particularly in England and Wales $[5,8]$. The reason for this high incidence is unknown. It is possible that children are less likely to have pre-existing immunity and would therefore tend to have relatively more symptomatic

\section{TABLE 2}

Characteristics of patients infected with Cryptosporidium species other than C. parvum and C. hominis, ANOFEL

Cryptosporidium National Network (ACNN), France, 2006-2009 (n=29)

\begin{tabular}{|c|c|c|c|c|c|c|}
\hline \multirow[b]{2}{*}{$\begin{array}{l}\text { Cryptosporidium } \\
\text { species or genotype }\end{array}$} & \multicolumn{6}{|c|}{ Patient characteristics } \\
\hline & Sex & $\begin{array}{c}\text { Age } \\
\text { (years) }\end{array}$ & $\begin{array}{l}\text { Immune status } \\
\left(\mathrm{CD}_{4} \text { counts per } \mathrm{mm}_{3}\right)^{\mathrm{a}}\end{array}$ & $\begin{array}{l}\text { Household } \\
\text { contacts with } \\
\text { diarrhoea }\end{array}$ & $\begin{array}{l}\text { Animal contact } \\
\text { (type of animal) }^{\mathrm{a}}\end{array}$ & $\begin{array}{l}\text { Travel history outside of } \\
\text { France (travel location) }\end{array}$ \\
\hline \multirow{15}{*}{ C. felis } & $M$ & 19 & HIV-infected (1) & No & No & No \\
\hline & M & 36 & HIV-infected (58) & ND & No & No \\
\hline & $\mathrm{F}$ & 40 & HIV-infected (7o) & No & No & Yes (Central African Republic) \\
\hline & $M$ & 33 & HIV-infected (116) & No & No & ND \\
\hline & $\mathrm{F}$ & 54 & HIV-infected («200) & Yes & No & No \\
\hline & $M$ & 64 & HIV-infected (856) & ND & Yes & Yes (Madagascar) \\
\hline & $\mathrm{F}$ & 41 & HIV-infected & No & No & No \\
\hline & $M$ & 61 & HIV-infected & No & Yes & No \\
\hline & $M$ & 41 & HIV-infected & No & No & ND \\
\hline & $M$ & 43 & HIV-infected (59) & No & No & No \\
\hline & M & 41 & Transplant recipient & No & No & No \\
\hline & $\mathrm{F}$ & 31 & Transplant recipient & Yes & No & No \\
\hline & $\mathrm{F}$ & 52 & Transplant recipient & No & Yes & No \\
\hline & $M$ & 22 & Immunocompetent & No & ND & Yes (Benin) \\
\hline & $M$ & 36 & Immunocompetent & Yes & ND & Yes (Canary Islands, Spain) \\
\hline \multirow{4}{*}{ C. meleagridis } & $M$ & 44 & HIV-infected & No & No & Yes (England) \\
\hline & ND & 1 & Immunocompetent & ND & ND & Yes (Cape Verde) \\
\hline & $M$ & 47 & Immunocompetent & No & Yes (wild animals) & Yes (Congo) \\
\hline & $M$ & 43 & HIV-infected (4) & No & No & ND \\
\hline \multirow{4}{*}{ C. canis } & $M$ & 36 & HIV-infected (27) & No & No & No, but living in Martinique \\
\hline & $M$ & 26 & Immunocompetent & ND & Yes & Yes (Niger) \\
\hline & $M$ & 49 & HIV-infected («100) & No & No & No \\
\hline & $\mathrm{F}$ & 41 & HIV-infected (3) & No & ND & Yes (Africa) \\
\hline Chipmunk genotype & $M$ & 41 & HIV-infected & ND & ND & ND \\
\hline Rabbit genotype & $M$ & 30 & HIV-infected (300) & ND & ND & ND \\
\hline New genotype (a) & $M$ & 34 & HIV-infected (21) & No & ND & Yes (Senegal and Guinea) \\
\hline New genotype (b) & $M$ & 57 & HIV-infected (15) & No & No & No \\
\hline New genotype (c) & $M$ & 86 & Myelodysplasia & No & ND & ND \\
\hline New genotype (d) & $M$ & 43 & HIV-infected (35) & No & Yes (bovines) & No \\
\hline
\end{tabular}

ANOFEL : French association of medical parasitologists; F: female; M: male; ND: not documented.

a If known. 
disease than adults. Moreover, young diarrhoeic children attend a physician more frequently and are also more easily hospitalised for rehydration therapy, thus increasing the chance of Cryptosporidium detection and notification.

Data reported here suggest a seasonal trend of cryptosporidiosis in France. Seasonal variations have also been seen in other countries $[4,5,10]$ and could be related to seasonal changes in the environment (e.g. the birth of farm animals) or to human behaviour that increase the risk of exposure (e.g. bathing in recreational water). Differences between the epidemiology of $C$. parvum and $C$. hominis are known $[8,17]$. Travel abroad, household contact with diarrhoea and untreated drinking water, already known to be significant risk factors for $C$. hominis infection $[8,17]$, were found in this study to be more frequently associated with $C$. hominis than $C$. parvum infection.

Cryptosporidium species other than C. parvum and C. hominis were identified in $9.4 \%$ of the patients analysed: most of them were HIV-infected. This proportion is in agreement with data from Caccio et al.: approximately $3 \%$ of 3,500 immunocompetent cryptosporidiosis cases and $19 \%$ of 600 immunocompromised cases, were infected with less common Cryptosporidium species (C. meleagridis, C. felis, C. canis, cervine genotype and monkey genotype) [18]. We also report here the first cases of human infection by $C$. canis and Cryptosporidium chipmunk genotype in France.

Our study has limitations associated with the hospitalbased structure of the ACNN. The patients studied by the network are probably more clinically patent cases of cryptosporidiosis as well as immunocompromised patients, who are admitted to hospital or who attend as outpatients from the surrounding towns. In the study, $70 \%$ of patients were hospitalised and $24.3 \%$ were not (not documented for $5.7 \%$ of patients, data not shown). This accounts for the overrepresentation of HIV-infected (although the proportion of cases with HIV infection halved over the study period) and immunocompromised patients and the probable patient age imbalance in our study. Indeed, from the annual record of the number of parasitological examinations that were performed by participating laboratories, which included the search of Cryptosporidium, the incidence of cryptosporidiosis in the population studied by the network can be estimated at $2.3 \%$ in $2006,1.48 \%$ in $2007,1.1 \%$ in 2008 and $1.96 \%$ in 2009 . But we cannot assume such incidence in the general population in France.

There are, in fact, several major difficulties in defining the real prevalence or incidence of cryptosporidiosis in France. First, the search for Cryptosporidium oocysts in stools is not routinely performed by laboratories unless requested by the treating physician. This probably accounts for misdiagnosis since healthcare practitioners may be not familiar with this practice and since cryptosporidiosis is still considered a rare disease in France, far less frequent than some other causes of diarrhoea. Obviously, there is a need for wide dissemination of comprehensive information on the epidemiology, risk factors and diagnosis of cryptosporidiosis among general practitioners and laboratory staff. The second reason is more technical, due to the difficulties encountered routinely by laboratories in the diagnosis of cryptosporidiosis, which requires skills and experience [19]. Interlaboratory tests performed within the ACNN (which comprise only experienced parasitology laboratories) initially showed some discrepancies between laboratories for diagnosis and parasite burden estimates (data not shown) and several interlaboratory blind tests were necessary to improve the sensitivity of detection when the level of oocyst shedding was low. Setting up interlaboratory tests at a national or European level would probably substantially improve the detection rate of Cryptosporidium in all laboratories. Alternatively, or to complement microscopy, other methods such as PCR or antigen detection could be used (several commercial test kits are available), but they are costly and the ability of some of these tests to detect all Cryptosporidium species needs to be ascertained.

This study, while providing new information about Cryptosporidium infection in hospitalised patients in France, does not provide sufficient denominator or comparative data to estimate the burden of disease. Extension of this study to a more representative sample of the French population, provision of information on diagnosis to practitioners, assessment of how well diagnosis is performed in laboratories and extension of the network to veterinarians is expected to lead to a better understanding of the epidemiology and transmission of cryptosporidiosis.

Members of the ANOFEL Cryptosporidium National Network (ACNN) in alphabetical order (except for coordinator and reference and genotyping centres)

Corresponding author: K Guyot (karine.guyot@pasteur-lille.fr), Pasteur Institute of Lille, Lille, France

Coordinator: F Derouin, Saint-Louis Hospital, Paris

Reference and genotyping centres: E Dutoit, University Hospital Centre (UHC), Lille, France; F de Monbrison, UHC, Lyon; K Guyot, Pasteur Institute of Lille, Lille.

Other members of the network: I Accoceberry, Saint-André Hospital, Bordeaux; P Agnamey, UHC, Amiens; A Angoulvant, Saint-Antoine/ Tenon Hospital, Paris; D Aubert, Maison Blanche Hospital, Reims; C Aznar, Andrée Rosemon Hospital, Cayenne, French Guiana; D Basset, UHC, Montpellier; P Beaudeau, InVS, Saint-Maurice, Paris; G Belkadi, Saint-Antoine Hospital, Paris; A Berry, Rangueil UHC, Toulouse; A Bonnin, Bocage Hospital, Dijon; F Botterel, Henri Mondor Hospital, Paris; M-E Bougnoux, Necker Hospital, Paris; P Bouree, Kremlin Bicêtre Hospital, Paris; P Buffet, Pitié Salpétrière Hospital, Paris; M Cambon, Hôtel-Dieu UHC, Clermont-Ferrand; B Carme, Andrée Rosemon Hospital, Cayenne, French Guiana; G Certad, Pasteur Institute of Lille, Lille; C Chartier, Afssa, Niort; B Couprie, Saint-André Hospital, Bordeaux; F Dalle, Bocage Hospital, Dijon; E Dannaoui, Georges Pompidou European Hospital, Paris; M-L Darde, Dupuytren UHC, Limoges; A Datry, Pitié Salpétrière Hospital, Paris; L de Gentile, UHC, Angers; E Dei-Cas, Pasteur Institute of Lille, Lille; B Degeilh, Pontchaillon Hospital, Rennes; N Desbois, UHC, Fort de France, Martinique; JM Dewitte, UHC, Lille; C Duhamel, Côte de Nacre UHC, Caen; TH Duong, Bretonneau Hospital, Tours; J Dupouy-Camet, Cochin Hospital, Paris; A Faussart, Bichat Hospital, Paris; L Favennec, Charles Nicolle Hospital, Rouen; P Flori, UHC, Saint Etienne; N Gantois, Pasteur Institute of Lille, Lille; G Gargala, Charles Nicolle Hospital, Rouen; F Grenouillet, Jean Minjoz Hospital, Besançon; M-L Grillot, UHC, Le Havre; D Haouchine, Bichat Hospital, 
Paris; S Houze, Bichat Hospital, Paris; D Jamet, Morvan UHC, Brest; $\mathrm{N}$ Kapel, Faculty of Pharmacy, Descartes University, Paris; M-D Linas, Rangueil UHC, Toulouse; D Magne, Saint-Antoine/Tenon Hospital, Paris; P Marty, UHC, Nice; C-J Mary, Timone Hospital, Marseille; J Menotti, St-Louis Hospital, Paris; M Miegeville, UHC, Nantes; G Nevez, Morvan UHC, Brest; M Nicolas, UHC, Pointe à Pitre, Guadeloupe; C Paraud, Afssa, Niort; C Pinel, A Michallon Hospital, Grenoble; P Poirier, Hôtel-Dieu UHC, Clermont-Ferrand; C Pomares-Estran, UHC, Nice; M Rabodonirina, UHC, Lyon; C Raccurt, UHC, Amiens; M-H Rodier, La Miletrie Hospital, Poitiers; C Sarfati, St-Louis Hospital, Paris; $M$ Thellier, Pitié Salpétrière Hospital, Paris; A Totet, UHC, Amiens; F Touafek, Pitié Salpétrière Hospital, Paris; O Villard, UHC, Strasbourg; I Villena, Maison Blanche Hospital, Reims; H Yera, Cochin Hospital, Paris.

\section{Acknowledgements}

The ANOFEL Cryptosporidium National Network (ACNN) is supported by a grant from InVS and ANOFEL. The genotyping was also supported financially by the French Ministry of Research (EA 3609). We thank Nathalie Lelieur for providing useful assistance in data analysis, Anthony Pinon for his advice on statistics and Annie Sulahian for English revision of the manuscript.

\section{References}

1. Chalmers RM, Davies AP. Minireview: clinical cryptosporidiosis. Exp Parasitol. 2010;124(1):138-46.

2. Pantenburg B, Cabada MM, White AC Jr. Treatment of cryptosporidiosis. Expert Rev Anti Infect Ther. 2009;7(4):385-91.

3. Karanis P, Kourenti C, Smith H. Waterborne transmission of protozoan parasites: a worldwide review of outbreaks and lessons learnt. J Water Health. 2007;5(1):1-38.

4. Semenza JC, Nichols G. Cryptosporidiosis surveillance and water-borne outbreaks in Europe. Euro Surveill. 2007;12(5). pii=711. Available from: http://www.eurosurveillance.org/ ViewArticle.aspx?Articleld $=711$

5. Nichols G, Chalmers R, Lake I, Sopwith W, Regan M, Hunter $P$, et al. Cryptosporidiosis: a report on the surveillance and epidemiology of Cryptosporidium infection in England and Wales. Drinking water Directorate Contract Number DWI 70/2/201. Drinking Water Inspectorate; 2006. Available from: http://www.dwi.gov.uk/research/completed-research/reports/ DWl70_2_201.pdf

6. Cardoen S, Van Huffel X, Berkvens D, Quoilin S, Ducoffre G, Saegerman C, et al. Evidence-based semiquantitative methodology for prioritization of foodborne zoonoses. Foodborne Pathog Dis. 2009;6(9):1083-96.

7. Majowicz SE, Michel P, Aramini JJ, McEwen SA, Wilson JB. Descriptive analysis of endemic cryptosporidiosis cases reported in Ontario, 1996-1997. Can J Public Health. 2001;92(1):62-6.

8. Chalmers RM, Elwin K, Thomas AL, Guy EC, Mason B. Longterm Cryptosporidium typing reveals the aetiology and species-specific epidemiology of human cryptosporidiosis in England and Wales, 2000 to 2003. Euro Surveill. 2009;14(2). pii: 19086. Available from: http://www.eurosurveillance.org/ ViewArticle.aspx?Articleld=19086

9. Snel SJ, Baker MG, Venugopal K. The epidemiology of cryptosporidiosis in New Zealand, 1997-2006. N Z Med J. 2009;122(1290):47-61.

10. Yoder JS, Beach MJ. Cryptosporidium surveillance and risk factors in the United States. Exp Parasitol. 2010;124(1):31-9.

11. Guyonnet J, Claudet J. Epidémie de gastro-entérite aiguë à Cryptosporidium liée à la pollution des eaux d'alimentation de la ville de Sète [Outbreak of acute Cryptosporidium gastroenteritis related to tap water pollution in Sète town]. Technique Science Méthodes 2002;97:23-29.

12. Di Palma M, Carbonel S, Beaudeau P, Checlair E, Gallay A. Epidémie de gastro-entérites à Cryptosporidium. Dracyle-fort, Saône et Loire (71) [Outbreak of Cryptosporidium gastroenteritis. Dracy-le-fort, Saône et Loire (71)]. Septembre 2001. DRASS de Bourgogne, CIRE de Dijon, Institut de veille sanitaire; 2001 . French. Available from: http:// fulltext.bdsp.ehesp.fr/Invs/Rapports/2003/rapport gastro. pdf?9WKDM-14J94-KKKG4-798KG-MoXG9
13. Gofti-Laroche L et Schmitt M. Epidémie de gastro-entérites liées à la pollution du réseau de distribution d'eau potable de la commune de Divonne-lesBains, Ain (01). Août-septembre 2003 [Outbreak of gastroenteritis related to the pollution of water distribution system in the commune of Divonne-lesBains, Ain (01)]. DRASS de Rhône Alpes, CIRE de Rhône Alpes Auvergne, Institut de Veille de veille sanitaire; November 2003. French. Available from: http://www.invs.sante.fr/ publications/2003/gea_divonne/gea_divonne_2003.pdf

14. Agence Française de Sécurité Sanitaire des Aliments (Afssa). Rapport sur les «Infections à protozoaires liées aux aliments et à l'eau »: "Evaluation scientifique des risques associés à Cryptosporidium sp. " [Report on 'Waterborne and foodborne protozoan infections': 'Scientific evaluation of the Cryptosporidium risks']. September 2002. French. Available from: http://www.afssa.fr/Documents/EAUX-Ra-Crypto.pdf

15. Smith HV. Diagnostics. In: Fayer R, Xiao L, editors. Cryptosporidium and cryptosporidiosis, 2nd ed. Boca Raton, FL: CRC Press and IWA Publishing; 2008. p. 173-208.

16. Xiao L, Bern C, Limor J, Sulaiman I, Roberts J, Checkley W, et al. Identification of 5 types of Cryptosporidium parasites in children in Lima, Peru. J Infect Dis. 2001;183(3):492-7.

17. Hunter PR, Hughes S, Woodhouse S, Syed Q, Verlander NQ, Chalmers RM, et al. Sporadic cryptosporidiosis case-contro study with genotyping. Emerg Infect Dis. 2004;10(7):1241-9.

18. Cacciò SM, Thompson RC, McLauchlin J, Smith HV. Unravelling Cryptosporidium and Giardia epidemiology. Trends Parasitol. 2005;21(9):430-7.

19. Cacciò SM, Pozio E. Advances in the epidemiology, diagnosis and treatment of cryptosporidiosis. Expert Rev Anti Infect Ther. 2006;4(3):429-43. 